\title{
The Phylogenetic Position of the Family Methylococcaceae
}

\author{
JOHN P. BOWMAN, ${ }^{*}$ LINDSAY I. SLY, AND ERKO STACKEBRANDT $\dagger$ \\ Center for Bacterial Diversity \& Identification, Department of Microbiology, The University of Queensland, \\ Brisbane, Queensland 4072, Australia
}

\begin{abstract}
The 16S ribosomal DNA-based phylogenetic positions of various members of the Methylococcaceae (group I methanotrophs) were investigated. The Methylococcaceae as a whole formed a distinct branch in the gamma subdivision of the Proteobacteria, and this branch had five distinct subbranches. On the basis of a number of phenotypic traits, phospholipid fatty acid patterns, and the results of a $16 \mathrm{~S}$ ribosomal DNA analysis, we determined that the species belonging to one subbranch, Methylobacter albus, Methylobacter agilis, and Methylobacter pelagicus, formed a distinct group that could be differentiated from other members of the genus Methylobacter, which grouped in an adjacent subbranch. We propose that these species belong to a new taxon, Methylomicrobium gen. nov.
\end{abstract}

Methanotrophs are organisms which obligately use $\mathrm{C}_{1}$ compounds, primarily methane, as sources of carbon and energy. Recently, workers have tried to clarify methanotroph relationships and have found that several methanotroph species are invalid and that the intergeneric relationships of these organisms are rather chaotic. Methanotrophs have been difficult to identify conclusively because information concerning their phenotypic and chemotaxonomic properties is limited. This has led to nomenclatural problems, especially problems concerning assignment of species to genera. Using a more thorough polyphasic taxonomic approach, workers have evaluated the species and genus organization of the methanotroph groups and have redefined several species and genera. This has resulted in emendation of the description of the genus Methylococcus and creation of the genus Methylobacter. The group II methanotrophs were elevated to official status in the form of the genera Methylocystis and Methylosinus (2). In this study we found that analysis of phospholipid fatty acid profiles was the best technique for identifying methanotrophs to the genus level; the results of phospholipid fatty acid profile analyses, in association with key phenotypic traits, could be used for effective identification of the various methanotrophic species. The phylogenetic relationships of various methanotrophs have also been investigated by using $5 \mathrm{~S}$ rRNA sequence analysis (1) and $16 \mathrm{~S}$ rRNA sequence analysis $(3,4)$. These sequence analyses revealed that there is significant heterogeneity among the members of the Methylococcaceae (group I methanotrophs), which apparently was reflected by the chaotic state of methanotroph nomenclature at the time of the studies. Although recent nomenclatural changes (2) have corrected some of the problems, in this study we used phylogenetic analysis to confirm and evaluate the recent nomenclatural changes made to members of the Methylococcaceae and to determine if additional nomenclatural changes are necessary.

All Methylomonas and Methylobacter strains except Methylobacter pelagicus strains were grown on nitrate mineral salts agar (2) under a methane-air- $\mathrm{CO}_{2}(5: 4: 1)$ atmosphere at $28^{\circ} \mathrm{C}$. Methylococcus strains were grown at $45^{\circ} \mathrm{C}$. Methylobacter pelagicus $\mathrm{NCMB} 2265^{\mathbf{T}}$ ( $\mathrm{T}=$ type strain) was grown on nitrate

\footnotetext{
* Corresponding author. Present address: Center for Environmental Biotechnology, The University of Tennessee, 10515 Research Dr., Suite 100, Knoxville, TN 37932.

$\dagger$ Present address: DSM-Deutsche Sammlung von Mikroorganismen und Zellkulturen GmbH, Mascheroder Weg 1B, D-38124 Braunschweig, Germany.
}

mineral salts medium that was prepared with seawater, solidified with $1.0 \%$ (wt/vol) agarose, and incubated at 22 to $25^{\circ} \mathrm{C}$. Genomic DNA was obtained from cells by freezing and thawing; centrifugation was used to remove cell debris. In vitro amplification of $16 \mathrm{~S}$ ribosomal DNA genes and subsequent sequencing of the amplicon were performed as described by Fuerst et al. (7). The regions of the $16 \mathrm{~S}$ ribosomal DNA sequences that could be aligned unambiguously (also referred to as the eubacterial mask) as described by Lane (8) were aligned; each sequence included 1,298 nucleotides. The PHYLIP (version 3.4) software package was used to determine evolutionary distances by the maximum-likelihood procedure. A phenogram was then constructed by using the Fitch-Margoliash algorithm (6). Sequences for the following organisms were determined in this study: Methylobacter agilis ACM $3308^{\mathrm{T}}$, Methylobacter albus ACM 3314 ${ }^{\mathrm{T}}$, Methylobacter luteus ACM 3304 ${ }^{\mathrm{T}}$, Methylobacter pelagicus ACM 3505 ${ }^{\mathrm{T}}$, Methylobacter whittenburyi ACM $3309^{\mathrm{T}}$, Methylococcus capsulatus Bath (= ACM 3302), Methylococcus capsulatus Texas $^{\mathbf{T}}$ (= ACM 1292 ${ }^{\mathrm{T}}$ ), Methylococcus thermophilus ACM 3585 ${ }^{\mathrm{T}}$, Methylococcus sp. strain JB140, Methylomonas aurantiaca ACM $3406^{\mathrm{T}}$, and Methylomonas fodinarum ACM $3268^{\mathrm{T}}$. Sequences for the following organisms were obtained from the GenBank/ EMBL data library: Arhodomonas oleiferhydrans ATCC $49307^{\mathrm{T}}$, Bathymodiolus thermophilus symbiont, Chromatium vinosum ATCC $17899^{\mathrm{T}}$, Calyptogenum magnifica symbiont, Codakia orbicularis symbiont, Coxiella burnetii, Deleya marina ATCC $25374^{\mathrm{T}}$, Ectothiorhodospira halophila DSM $244^{\mathrm{T}}$, Escherichia coli, Halomonas elongata ATCC 33173, Legionella pneumophila subsp. pneumophila ATCC 33152, Louisiana mytilid symbiont (group Ia), Lucinoma aequizonata symbiont, "Methylobacter bovis" 89, Methylobacter marinus ACM 4377 " "Methylobacter vinelandii" 87, Methylomonas methanica ACM $3307^{\mathrm{T}}$ (Carl Woese, University of Illinois, Champaign-Urbana), "Methylomonas rubra" ACM 3303, Methylomonas sp. strain 761M (= NCIMB 11931), Nitrosococcus oceanus ATCC $19707^{\mathrm{T}}$, Oceanospirillum linum ATCC $11336^{\mathrm{T}}$, Pseudomonas aeruginosa ATCC $10145^{\mathrm{T}}$, Solemya reidi symbiont, Thiobacillus ferroxidans DSM 2392, and Thyasira flexuosa symbiont.

Methylococcaceae phylogeny. The taxonomic relationships of previously described group I methanotrophs that were classified as members of the family Methylococcaceae (2) were investigated by comparing their $16 \mathrm{~S}$ ribosomal DNA sequences. This form of analysis was also used to fully confirm and justify previous taxonomic proposals (2). Figure 1 shows an unrooted phylogenetic tree in which the Methylococcaceae 


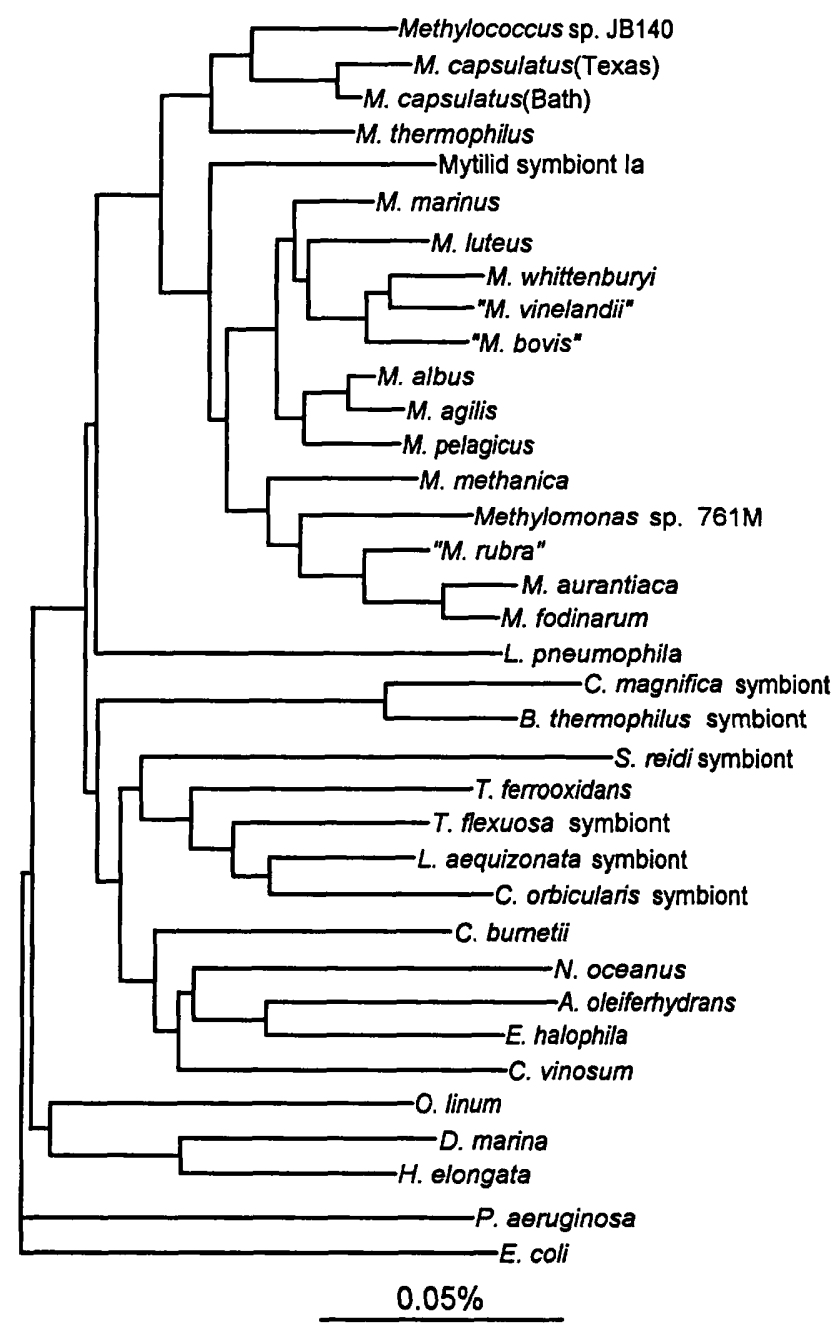

FIG. 1. Unrooted phylogenetic tree showing relationships among members of the family Methylococcaceae and other members of the gamma subdivision of the Proteobacteria.

forms a distinct line of descent within the gamma subdivision of the Proteobacteria. The closest relatives of the Methylococcaceae clade included the genera Legionella and Coxiella, various free-living and endosymbiotic chemoautotrophic bacteria, and, slightly more distantly, the Halomonadaceae.

On the basis of phylogenetic analysis data we divided the Methylococcaceae into five subbranches (Fig. 1). The first subbranch included the moderately thermophilic Methylococcus species, including Methylococcus capsulatus and Methylococcus thermophilus. Strain JB140, which is no longer extant, was isolated from river mud and was able to grow on a wide variety of $C_{1}$ compounds. The second subbranch included the methanotrophic endosymbiont of a mytilid found growing in hydrocarbon cold seeps on the Louisiana Slope in the Gulf of Mexico (5); the length of this subbranch clearly shows that the methanotrophic endosymbiont represents a distinct genus, and research is being performed with other similar strains to confirm this (5). The third subbranch included desiccation cyst-forming species belonging to the genus Methylobacter. The results of DNA-DNA hybridization experiments have shown previously that Methylobacter whittenburyi and "Methylobacter vinelandii" are closely related; in fact, "Methylobacter vinelan- dii" has been declared a synonym of Methylobacter whittenburyi (2). Some strains of "Methylobacter bovis" have also been found to be phenotypically diverse, and "Methylobacter bovis" (type strain, IMV-B 3098) has been found to be a synonym of Methylobacter luteus (2). "Methylobacter bovis" 93, whose sequence was determined by Brusseau et al. (4), is more closely related to Methylobacter whittenburyi, as is "Methylobacter bovis" IMET-10593 (2). The fourth subbranch included noncyst-forming Methylobacter species; on the basis of the results of our phylogenetic analysis and after consideration of other pertinent characteristics, these species did not seem to be related to other Methylobacter species at the genus level (see below). The final subbranch included the carotenoid-containing Methylomonas species, including the pink-pigmented species, Methylomonas methanica and two orange-pigmented species, Methylomonas aurantiaca and Methylomonas fodinarum. The results of our phylogenetic analysis placed "Methylomonas rubra" ACM 3303 adjacent to the orange-pigmented species, while the unusual glucose-metabolizing variant strain $761 \mathrm{M}(9)$ is quite distinct; this organism may represent a distinct species. A previous numerical analysis revealed that "Methylomonas rubra" ACM 3303 is essentially indistinguishable phenotypically from Methylomonas methanica (2). More intensive DNADNA hybridization analyses must be performed to fully elucidate the exact taxonomic status of Methylomonas sp. strain $761 \mathrm{M}$ and "Methylomonas rubra" strains.

Proposal for Methylomicrobium gen. nov. The results of a previous 5S rRNA analysis indicated that the species Methylobacter agilis and Methylobacter albus are quite distinct from other Methylobacter species (2). These species and the marine species Methylobacter pelagicus can be distinguished readily from other Methylobacter species by using key differential traits (Table 1). The most important features which characterize these species includes their inability to form cysts, their lack of pigmentation, and the presence of a distinct phospholipid fatty acid profile. The phospholipid fatty acid profile, with its low level of tetradecanoate $(<2 \%)$, distinguishes the organisms that do not form cysts from Methylomonas spp., while the high levels of different 16-carbon monoenoic fatty acids distinguish them from Methylobacter and Methylococcus spp. On the basis of these differences, the species Methylobacter agilis, Methylobacter albus, and Methylobacter pelagicus form a distinct genus, for which we propose the name Methylomicrobium gen. nov.

Description of Methylomicrobium gen. nov. Methylomicrobium (Me. thyl.o.mi. cro'bi.um. Fr. n. méthyle, methyl radical; Gr. adj. micros, small; Gr. n. bios, life; M. L. neut. n. Methylomicrobium methyl microbe). Gram-negative rods that are 0.5 to $1.0 \mu \mathrm{m}$ wide and 1.5 to $2.5 \mu \mathrm{m}$ long. Cells are motile by means of a single polar flagellum, reproduce by binary fission, and do not contain cysts or other resting bodies. Colonies are either translucent and nonpigmented or opaque white. Strictly aerobic chemoheterotrophs which utilize methane and methanol. Some strains can utilize mono- and dimethylated amines as sole carbon and energy sources. No carbon-carbon-bonded compounds are utilized. No growth occurs on organic media. Dissimilatory methane oxidation is associated with intracytoplasmic membranes which have the appearance of stacks of vesicular discs. Strains do not fix nitrogen and do not contain Benson-Calvin cycle enzymes. The major fatty acids include a variety of 16-carbon monoenoic fatty acids; significant levels of tetradecanoate are not present. The major respiratory quinone is ubiquinone 8 . The $\mathrm{G}+\mathrm{C}$ contents of the DNAs range from 49 to $60 \mathrm{~mol} \%$ (as determined by the $T_{i}$ method).

Description of Methylomicrobium agile (Bowman, Sly, Nichols, and Hayward 1993) comb. nov. A complete description 
TABLE 1. Characteristics that differentiate genera belonging to the family Methylococcacea $e^{a}$

\begin{tabular}{|c|c|c|c|c|}
\hline Characteristic & Methylomonas & Methylobacter & $\begin{array}{l}\text { Methylomicrobium } \\
\text { gen. nov. }\end{array}$ & Methylococcus \\
\hline \multicolumn{5}{|l|}{ Cell morphology } \\
\hline Rods & $t^{b}$ & - & + & - \\
\hline Cocci or ellipsoids & - & + & - & + \\
\hline Motility & + & $\mathrm{D}$ & + & $\mathrm{D}$ \\
\hline Carotenoids formed & + & - & - & - \\
\hline Brown or yellow pigmentation ${ }^{c}$ & - & + & - & + \\
\hline \multicolumn{5}{|l|}{ Cyst formation } \\
\hline Desiccation sensitive & + & - & - & + \\
\hline Desiccation resistant & - & + & - & - \\
\hline Growth at $45^{\circ} \mathrm{C}$ & - & - & - & + \\
\hline $\begin{array}{l}\text { Ribulose-1,5-diphosphate } \\
\text { carboxylase }\end{array}$ & - & - & - & + \\
\hline Nitrogen fixation & $\mathrm{D}$ & - & - & + \\
\hline \multicolumn{5}{|l|}{ Major phospholipid fatty acids } \\
\hline $14: 0$ & $22 \pm 3^{d}$ & $9 \pm 2$ & $1 \pm 1$ & $1 \pm 1$ \\
\hline $16: 1 \omega 8 c$ & $30 \pm 11$ & 0 & $16 \pm 3$ & 0 \\
\hline $16: 1 \omega 7 c$ & $11 \pm 4$ & $57 \pm 1$ & $17 \pm 3$ & $28 \pm 10$ \\
\hline $16: 1 \omega 6 c$ & $9 \pm 4$ & $5 \pm 1$ & $10 \pm 4$ & $3 \pm 2$ \\
\hline $16: 1 \omega 5 c$ & $4 \pm 2$ & $7 \pm 1$ & $6 \pm 1$ & $3 \pm 2$ \\
\hline $16: 1 \omega 5 t$ & $12 \pm 4$ & $11 \pm 1$ & $20 \pm 10$ & $<1$ \\
\hline $16: 0$ & $7 \pm 2$ & $8 \pm 1$ & $15 \pm 3$ & $44 \pm 8$ \\
\hline
\end{tabular}

${ }^{a}$ Data from reference 1 .

${ }^{b}+$, positive; - , negative; $\mathrm{D}$, characteristic varies among species.

${ }^{c}$ Pigments are often diffusible.

${ }^{d}$ Values are percentages of the total phospholipid fatty acids (average \pm standard deviation).

of Methylomicrobium agile is given in reference 1 . The type strain is strain ACM 3308 (= ATCC 35068 = NCIMB 11124).

Description of Methylomicrobium album (Bowman, Sly, Nichols, and Hayward 1993) comb. nov. A complete description of Methylomicrobium album is given in reference 1 . The type strain is strain ACM 3314 (= NCIMB $11123=$ VKM-BG8).

Description of Methylomicrobium pelagicum (Sieburth et al. 1987) Bowman, Sly, Nichols, and Hayward 1993 comb. nov. A complete description of Methylomicrobium pelagicum is given in reference 1. The type strain is strain ACM 3505 (= NCIMB 2265).

Because of the transfer of Methylobacter albus, Methylobacter agile, and Methylobacter pelagicus to a new genus, the description of the genus Methylobacter (2) should be emended. An emended description of this taxon is given below.

Description of the genus Methylobacter (Bowman, Sly, Nichols, and Hayward 1993) emend. Gram-negative cells are spherical to oval or ellipsoidal $(1.0$ to $1.5 \mu \mathrm{m}$ wide and 1.5 to $3.0 \mu \mathrm{m}$ long) and reproduce by binary division. Often nonmotile, but motile strains do occur. Motile strains always possess a single polar flagellum. Each cell can form a desiccationresistant cyst, especially in the stationary growth phase. The cysts survive 30 days of drying and appear to be similar to cysts found in members of the genus Azotobacter. Strains are either bright yellow (Methylobacter luteus) or tan to brown and form a brown diffusible pigment during extended incubation. Strictly aerobic chemoheterotrophs which utilize only methane and methanol. No carbon-carbon-bonded compounds are utilized. No growth occurs on organic media. Dissimilatory methane oxidation is associated with intracytoplasmic membranes which have the appearance of vesicular discs. Strains do not fix nitrogen and do not contain Benson-Calvin cycle enzymes. The major fatty acid is $16: 1 \omega 7 c$. The major respiratory quinone is ubiquinone 8. The $\mathrm{G}+\mathrm{C}$ contents of the DNAs range from 49 to $54 \mathrm{~mol} \%$ (as determined by the $T_{i}$ method).

The nucleotide sequences determined in this study have been deposited in the EMBL, Heidelberg, Germany, under the following accession numbers: Methylobacter agilis ACM $3308^{\mathrm{T}}$, X72767; Methylobacter albus ACM 3314 ${ }^{\mathrm{T}}$, X72777; Methylobacter luteus ACM 3304 ${ }^{\mathrm{T}}$, X72772; Methylobacter pelagicus ACM 3505 ${ }^{\mathrm{T}}$, X72775; Methylobacter whittenburyi ACM $3309^{\mathrm{T}}$, X72773; Methylococcus capsulatus Bath (= ACM 3302, X72771; Methylococcus capsulatus $\operatorname{Texas}^{\mathrm{T}}\left(=\mathrm{ACM} 1292^{\mathrm{T}}\right)$, X72770; Methylococcus thermophilus ACM 3585' ${ }^{\mathrm{T}}$, X73819; Methylococcus sp. strain JB140, X72769; Methylomonas aurantiaca ACM 3406 ${ }^{\mathrm{T}}, \mathrm{X} 72776$; and Methylomonas fodinarum ACM $3268^{\mathrm{T}}, \mathrm{X} 72778$. The accession numbers for sequences obtained from the GenBank/EMBL data library are as follows: Arhodomonas oleiferhydrans ATCC $49307^{\mathrm{T}}$, M26631; Bathymodiolus thermophilus symbiont, M99445; Chromatium vinosum ATCC 17899'T, M26629; Calyptogenum magnifica symbiont, M99446; Codakia orbicularis symbiont, M99447; Coxiella burnetii, M21291; Deleya marina ATCC 25374 ${ }^{\mathrm{T}}$, M93354; Ectothiorhodospira halophila DSM 244 ${ }^{\mathrm{T}}$, M26630; Escherichia coli, J01695; Halomonas elongata ATCC 33173, M93355; Legionella pneumophila subsp. pneumophila ATCC 33152, M59157; Louisiana mytilid symbiont (group Ia), U05595; Lucinoma aequizonata symbiont, M99448; "Methylobacter bovis" 89, L20839; Methylobacter marinus ACM 4377 , M95658; "Methylobacter vinelandii" 87, L20841; Methylomonas methanica ACM $3307^{\mathrm{T}}$ (Carl Woese, University of Illinois, Champaign-Urbana), unpublished; "Methylomonas rubra" ACM3303, M95662; Methylomonas sp. strain 761M (= NCIMB 11931), L20846; Nitrosococcus oceanus ATCC $19707^{\mathrm{T}}$, M96395; Oceanospirillum linum ATCC 11336' ${ }^{\mathrm{T}}$, M22365; Pseudomonas aeruginosa ATCC 10145 ${ }^{\mathrm{T}}$, M34133; Solemya reidi symbiont, L07864; Thiobacillus ferroxidans DSM 2392, M79416-7; and Thyasira flexuosa symbiont, L01575.

\section{REFERENCES}

1. Boulygina, E. S., K. M. Chumakov, and A. I. Netrusov. 1993. Systematics of Gram-negative methylotrophic bacteria based on 5S rRNA sequences, p. 275-283. In J. C. Murrell and D. P. Kelly (ed.), Microbial growth on $C_{1}$ compounds. Intercept, Ltd., Andover, England.

2. Bowman, J. P., L. I. Sly, P. D. Nichols, and A. C. Hayward. 1993. Revised 
taxonomy of the methanotrophs: description of Methylobacter gen. nov. emendation of Methylococcus, validation of Methylosinus and Methylocystis species, and a proposal that the family Methylococcaceae includes only the group I methanotrophs. Int. J. Syst. Bacteriol. 43:735-753.

3. Bratina, B., G. A. Brusseau, and R. Hanson. 1992. Use of 16S rRNA analysis to investigate phylogeny of methylotrophic bacteria. Int. J. Syst. Bacteriol. 42:645-648.

4. Brusseau, G. A., E. S. Bulygina, and R. S. Hanson. 1994. Phylogenetic analysis and development of probes for differentiating methylotrophic bacteria. Appl. Environ. Microbiol. 60:626-636.

5. Distel, D. L., and C. M. Cavanaugh. 1994. Independent phylogenetic origins of methanotrophic and chemoautotrophic bacterial endosymbionts in marine bivalves. J. Bacteriol. 176:1932-1938.
6. Felsenstein, J. 1982. Numerical methods for inferring evolutionary trees. Q. Rev. Biol. 57:379-404.

7. Fuerst, J. A., J. A. Hawkins, A. Holmes, L. I. Sly, C. J. Moore, and E. Stackebrandt. 1993. Porphyrobacter neustonensis gen. nov., sp. nov., an aerobic bacteriochlorophyll-synthesizing budding bacterium from freshwater. Int. J. Syst. Bacteriol. 43:125-134.

8. Lane, D. J. 1991. 16S/23S rRNA sequencing, p. 115-176. In E. Stackebrandt and M. Goodfellow (ed.), Nucleic acid techniques in bacterial systematics. John Wiley \& Sons, New York.

9. Zhao, S. J., and R. S. Hanson. 1984. Variants of the obligate methanotroph isolate $761 \mathrm{M}$ capable of growth on glucose in the absence of methane. Appl. Environ. Microbiol. 48:807-812. 